\title{
TEACHING MATTERS: GRADUATE STUDENT VOICES FROM BEHIND THE DESK
}

\section{(Some of) The Editors}

Here at the University of Iowa, graduate students from an array of disciplines are entrusted with the responsibility of teaching thousands of undergraduates every semester. For many of us, teaching is one of the most important things we do. But for the most part, the invaluable teaching graduate students do is under-appreciated, belittled, or ignored. Moreover, graduate student voices are infrequently heard with regard to teaching matters, our perspectives and experiences are not often articulated in public forums. What follows is an attempt to rectify this situation, to begin a dialogue.

\section{AH, AMBIVALENCE}

Daniel Nathan

Ambivalence gnaws at me when I think about my graduate student teaching experience. I have been a teaching assistant here at the University of Iowa (UI) for the past five years and I understand that my labor has been exploited. I am also aware that what I have gained in terms of "collegiality" does not make up for what I have lost in terms of income and benefits. And as a result I support the Campaign to Organize Graduate Students (COGS) and its attempt to unionize graduate employees. But it is also important to express my indebtedness and gratitude to the UI, and the American Studies Program in particular, for giving me opportunities to teach a variety of courses (a few of which were self-designed "topics" courses, such as "The Sweet Science: Boxing in American Culture" and "American History, Literature, \& Culture in the 1950s"), and thus to find out what it means to be on the other side of the desk, to be solely responsible for what goes on in a college classroom. Indeed, teaching has probably taught me as much about the profession to which I aspire as any graduate seminar ever could. Hopefully it has enhanced my job prospects (in a field where prospects are abysmal) and it has certainly enriched me personally. For these and other reasons being a teaching assistant-which is a completely inadequate description of the job as I 
and many others know it - has been a valuable and important aspect of my years here. At the same time there is little doubt that teaching has significantly slowed my progress toward my degree. And so every so often I am forced to ask myself, has it been worth it? I know that teaching matters, but am I really here to teach or am I here to be taught, to earn a degree, and to (try to) enter a profession? It is, of course, too soon to answer these questions with any certainty, but at this point I want to say: yes, it has been worth it; yes, I am here to teach; yes, teaching is an important part of my education. I want to believe that even in a worst case scenario- that is, I am one of the approximately 50 percent of Ph.D.s who never land a tenure-track academic position - that it has been worth it, that the experience has been enriching enough for its own sake, as well as for subsidiary reasons. After all, I have learned that teaching teaches humility and promotes empathy, respect, and admiration for other teachers. It has also taught me that teaching and learning are inseparable. Teaching constantly reminds me that, as Gilbert Highet put it nearly fifty years ago: "We are all pupils and we are all teachers." In short, I want to believe, in the face of a dire job market, that my graduate student teaching experience has been profitable, that I have not wasted years of my life designing syllabi, leading discussions, and grading papers. Idealism dies hard, ambivalence endures.

\section{VOCATIONAL ED.}

\section{Dallas Clemmons}

I taught high school for five years before coming to the University of Iowa as a graduate student. For five years I was known as "Mr. Clemmons." I wore a tie and carried a briefcase; I attended faculty meetings and parent conferences and education workshops; I created syllabi and quizzes and final exams. Every weekday from mid-August to mid-May I arrived at school at 7:30 A.M., stayed until 4 P.M., and taught five classes of 10th and 12th grade English. I knew my students well: I knew their families, their expectations and objectives, their tastes in music and movies. I knew their strengths and weaknesses as readers and writers; I knew how they were doing in other classes and sports and extracurricular activities. My students, and my classes, were an important part of my life.

I went into teaching because I realized that sitting in a classroom talking about literature and popular culture seemed like a perfect way to spend my time. I liked doing it as a student and felt I'd like it from the other side of the desk. And I was right. Whenever I was in the classroom I truly felt that I had done what Robert Frost urged: united my avocation with my vocation. My students were, for the most part, bright and, more important, interested. I wouldn't have enjoyed teaching had it meant spending my days telling surly teenagers to sit down and shut up, or chastising kids for smoking in the bathrooms. I also wouldn't have enjoyed it if it meant spending countless hours correcting papers with comments that would go unread, or trying to run discussions on texts that no one had opened. But that was not the case at the high school where I taught: I often had to work long hours to be sure, but it truly didn't seem like work to grade an essay knowing that the student cared about what I had to say. It didn't seem like work to walk into my 
classroom knowing I could throw the text open, quote a passage, and start a discussion that easily.

But I left that school and decided to pursue a Ph.D. because I came to feel that I would enjoy college teaching more. I wrote my application essay on that subject and my first surprise, upon arriving here, was when a faculty member told me how "unique" and "interesting" my essay had been. Why? Because I had stressed that I wanted to teach. It wasn't long before I realized that, for many of my fellow graduate students, as well as senior faculty, the word "undergraduate" was analogous to "encumbrance." Teaching was an unavoidable burden. Students took up your time! They knocked on your door! They kept you from doing your real work!

This isn't necessarily representative of the way most graduate students and faculty feel, but it is something I've encountered more often than not. And it should be stressed that a lot of the "real work" that these people do is important, and that the system is set up so that they, in fact, can't do that work unless they teach as well. That's unfortunate. But equally unfortunate, I think, is that the teaching experience for many graduate students here at the university is, overall, a negative experience. The classes we are given to teach are frequently the classes that students are forced to take, so many of them aren't interested or motivated. We rarely get to know the students (while I'm still in contact with some of my high school students from seven years ago, it isn't unusual here for a former student to pass me on the sidewalk without a flicker of recognition); we rarely get positive reinforcement or feedback. The term "TA" seems to generate indifference at best or disrespect at worst from students, their parents, and the Iowa state Board of Regents. As the system now stands, it's a self-perpetuating problem. Teaching is something we do on the side, and when we do it, it often isn't a terribly positive experience.

What can be done? These problems clearly need a lot more discussion than we have room for here. But allowing graduate students to teach more topics courses - allowing us to spend our time in the classrooms discussing what interests us the most, sharing our passions-would be a good start. That's why I chose to become a teacher, after all; that's where the fun is. Yes, we need the money (or "aid," to use the proper euphemism) and yes, the university needs the grunt labor for teaching these classes few students want to take. But our teaching experiences should comprise more than grunt labor. Otherwise, I fear too many of us burn out on this profession before we ever begin.

\section{MAKING TEACHING MATTER}

Leslie Taylor

It is no wonder that graduate employees at the University of Iowa (UI) are unionizing - it is only surprising that we did not act sooner. I joined the Campaign to Organize Graduate Students (COGS) in April 1993 after I had been a teaching assistant (TA) for three years. Becoming part of a graduate student union was an easy decision since one-fourth of my salary went back to the university to pay for tuition, I received paltry raises and no real health care plan.

I had never before been a union member even though my mother was a Team- 
ster and my father was in the musician's union. I knew not to cross a picket line, but even as a secretary I had never joined a union. That changed when I became a TA and experienced the disparate treatment graduate employees receive. As a part-time secretary at the UI, I received a comprehensive health care plan that included dental and optical coverage; I also received a pension plan and accrued vacation and sick leave. If I had remained in my secretarial position or been classified as an adjunct faculty member, I would have retained my benefits. Instead, I lost it all when I chose to become a TA.

I came into COGS-UE concerned about remedying these inequities, but serving in the union has made me clarify my role as an intellectual worker and understand better the potential for creating cultural change in the academy. Many of us have sat around seminar tables together and debated Foucauldian definitions of power, the political efficacy of Marxism, the social construction of identities, and definitions of "resistance." Those of us who want to effect change have also discussed whether it is more effective to be teachers and scholars in the academy, or if we should be "out there" in the "real world." I made a decision to return to the academy after working "out there" when I realized teaching and scholarship could be political acts and my commitments as an "academic" and "activist" were the same. My decision to teach "Lesbian Lives," for example, is based on an overtly political position about queer visibility and a commitment to bringing sexuality studies into the academy.

Certainly creating courses, choosing texts, and implementing feminist pedagogy are inherently political acts. But my participation in COGS has made me articulate new connections between the university's policies, my own life, and my student's lives. As the future of higher education grows increasingly precarious, I fear that the democratization of higher education achieved through the vast system of public universities is being eroded. Tuition and resident hall fees increase, family incomes drop, and federal financial aid programs are slashed as debt levels soar for both undergraduates and graduate employees. Who will be in my classroom and who will not? Who will get to TA and who will not? How will their absence affect what is learned or taught in the classroom?

I hear the language of downsizing becoming the dominant discourse on this campus and see health sciences staff lose their jobs in the name of "competitiveness" and some arbitrary "bottom line." TAs should take note: I hear the same rhetoric applied to courses like "Interpretation of Literature" and "American Values." Administrators see large lecture halls with "faculty" contact as a solution to tight budgets. Rather than expanding the number of small classes with a teacher/student ratio of $23: 1$ or $25: 1$, the administration appears prepared to compromise undergraduate education and cavalierly dismiss the TAs who depend on teaching to finish their degrees.

A graduate student union cannot fix this deplorable situation overnight, but COGS-UE can become a site from which we can make interventions. Certainly we can demand-and win-better salaries and benefits for ourselves. We can also demand better funding for higher education, including more tenure track faculty, an end to tuition increases for both undergraduates and graduate stu- 
dents, small class sizes, and better funding of our libraries and research facilities. We can also create leverage on the administration to achieve real diversity in our student populations and faculty beyond the woeful goals currently set.

When I enter the classroom again this fall, with a COGS-UE union card in my pocket, I will also be there with a commitment to improving the experience and expanding the accessibility of higher education for other young women and men. Winning a graduate student union will be a major step to re-envisioning the future of higher education at the University of Iowa.

\section{THE WORK OF THE PROFESSOR IN THE AGE OF MECHANICAL REPRODUCTION: THOUGHTS ON INSTRUCTION}

Dean Auvauld

It is a melancholy object to those who walk the halls of academe to behold the long, callow faces of disaffected youth who have been denied the promise of an education. It saddens me to watch them file in and out of classrooms, headphones in place, caps shadowing their countenances. I recall my own salad days, when education was coveted and the opportunity for intellectual inquiry was cherished. Given the current state of the university, student's apparent indifference does not surprise me. Though my recollections are undoubtedly tainted by nostalgia, I cannot help but feel that the students' lack of enthusiasm signals that we in the university have lost a sense of how to faithfully execute our mission to educate future generations. It is my hope in the subsequent pages to elaborate on this breach of promise and put forth reasoned propositions by which we might address it.

I think it is agreed by all parties that we are experiencing a crisis in American education. The last two decades have been characterized by a highly volatile series of changes in curriculum, adjustments in departmental policy, and debates over the role of the university in contemporary society. It is equally certain that many of these alterations represent corrections of previous imbalances; for example, the canon has surely benefited from the admittance of minority writers and artists. Nonetheless, in the aftermath of these changes the humanities have been left uncertain of how to define themselves, and the traditional disciplines in both the arts and the sciences have come dangerously close to extinction. Indeed, one might wonder if the malaise of the contemporary student is a product of the splintering of traditional subjects and discourses. The numb expressions on the faces of these students might well represent uncertainty about what to read, what to see, what to think, and even why they are here.

Please forgive this cursory glance at a series of topics that are each worthy of an editorial unto themselves. As a member of the university community for these thirty-eight years, however, I feel particularly compelled to address what is for me the foundational issue before us: graduate student teaching. As an undergraduate, I confess that I regarded my own professors as unimpeachable sources of insight and experience who seemed to consistently anticipate my every inquiry or challenge. Later, as a graduate student, I began to realize how I might support and inform the work of my mentors. But in my years as a professor I have 
seen graduate student instructors become increasingly emboldened to interrogate the authority of tenured faculty and the integrity of the discipline itself. I trust I need not explain that experienced professors provide an irreplaceable expertise and perform a crucial role in the shaping of our standards of taste and judgment. I cannot, we must not, concede the responsibility to our professional and cultural heritage. It has long been the privilege of teachers to ensure the safe passage of this inheritance. The question at hand seems to be: how might we ensure the quality of our teaching and reinstill in our students the thirst for knowledge and respect for those who disseminate it?

With this in mind, I shall now therefore humbly enumerate what I consider to be the three most pressing threats to the integrity of the academy.

First: Students do not consistently have access to this repository of professorial knowledge. Due to such unavoidable factors as unprecedented numbers of matriculated students, combined with cutbacks in university budgets, an increased emphasis on research, and the unfortunate demise of scores of talented professors, our young people all too often find themselves face to face with a graduate instructor little more experienced than themselves. While I have no doubt that these graduate instructors are enthusiastic, intelligent and committed, I fear that their tendency towards wide-eyed recklessness and faithless polemic suggests that they have been sent before their time "into this breathing world, scarce half made up." Not only are undergraduates deprived of the wealth of information a fully formed intellect has at its disposal, but they are denied the pleasure of witnessing that mind at work. The wizened visage of the professor is a beacon to the student who might otherwise have lost his or her way.

Second: Perhaps the most unfortunate consequence of the marked absence of professors in the classroom is a largely ungoverned corps of graduate instructors. While I am certain there are respectful instructors, I suspect too many imagine the classroom as a place of improvisation where they might interrogate even the most steadfast of truths. Caught in the cross-hairs of a debate between multiculturalism and an assault on political correctness, these instructors frequently tap dance from one critical posture to the next. Judging by the steady rise in student grade complaints and the increasingly publicized debates over classroom materials and "revised" reading lists, we must institute some measure of vigilance. These courses can no longer remain unsupervised.

Third: In the absence of an established canon, curricular chaos reigns in many of today's graduate student classrooms. Without firm institutional guidance, we have witnessed the introduction/instruction of myriad works of dubious merit. In the interest of increased political and cultural awareness, we are forsaking investigations of knowledge and truth. If you look at the reading lists of several sections of the same course you can see how personal taste has replaced traditional values as a standard for inclusion in the curriculum. Judging by the recent episodes with explicit foreign films we can see that it is unfortunate but true that some of our young colleagues are more interested in being titillating than instructive. I hold that it is our solemn responsibility as the overseers of this academy to ensure that such outrageousness comes to an end. 
In light of these problems, I offer the following solution, which I hope will not be libel to the least objections.

As I mentioned earlier, with the unfortunate passing of many of our best professors in recent years, we in the academy are left to negotiate an irreparable loss. Or are we? I have been assured by a very knowing English colleague of mine in the sciences that we are now fully capable of saving our traditions in a remarkable if somewhat unusual manner. Medical science has advanced to the point that the human corpus might be preserved for years after its demise. While it is perhaps unseemly to exhume fallen fellows from their earthly resting places, it is assuredly wise to begin a program whereby we might register for preservation those members of the teaching community who are about to close the book on their academic lives (we might also secure the rights to the bodies of those most recently passed). Once we have identified a sufficient reserve of candidates, we can begin a much needed effort to supplement our current faculties with a program of what I will call taxidermic pedagogy.

Consider the countless benefits of this plan. Envision the sage, embalmed in natty attire, who leans precariously yet confidently upon the anchored podium. Such a professor is a model of composure, poise, and patience; he is unyielding in his positions and confident of his stature. Furthermore he is never swayed by appeals to emotion or impertinent entreaties of special interest. He will not dance around the volatile issues nor surrender his hold upon knowledge and truth. He is the stuff of sound pedagogy. In short, he provides an unfailing presence of authority that is missing from the lives of many undergraduates.

As universities attempt to replace the considerable experience of professorial guidance with the relative whimsy of graduate student instruction, an unfortunate consequence is the loss of professorial aura which lends authenticity to the educational experience. It marks the difference between a class which is transcendent and one which is merely informative. It restores the ritual of learning to the classroom and commands a crucial measure of respect and reverence. As the taxidermic registry develops, class-size would diminish and professor-student ratio plummet to an ideal range. After several years, individual tutorials would be possible. As we increase our non-salaried staff (perhaps there would be a small stipend for the beneficiaries), the goal of graduating our students in four years or less is eminently attainable. We might increase other university programs by cutting back on sabbaticals and travel stipends for these candidates and the "hiring season" might take place year round. Many students, for years to come, would have the chance to work with the prized professors which thereby guarantee the university's reputation in the future. As the program develops, we may look forward to an inner-university loan program whereby access to great minds and their expertise would become universally available.

My colleague in London, a true lover of the academy whom I highly esteem, helped me to see the further virtues of taxidermic pedagogy. It will, for instance, help to quell the chaos surrounding course materials. An experienced sentry in each classroom would ensure the stability of the canon and the neutrality of artistic expression. By introducing the fixed qualities of good taste and decorum, we 
ensure a progression toward a more mainstream curriculum. While the classroom is an appropriate site for dialectical reasoning, it ought not to be an arena for the thoughtless expression of intense and conflicting passions. Do not misunderstand, I recognize that many of our great works inspire various enthusiasms. I too have dreamt of my own Roman tryst with Daisy Miller and have gazed at Picasso's “Three Dancers” with a certain, shall we say, amoré, but let us leave the teaching of sexuality to the Biology department. Having shuffled off this mortal coil, our esteemed colleagues will not be prone to develop vested interests or personal agendas which might unnecessarily prejudice explication. We should strive, at all costs, for interpretive neutrality. And yet, I worry that we have not yet devised a means of assuring responsible conduct on the part of graduate instructors who are serving their apprenticeships in this shop of auras. It is toward this end that I make my final turn.

My friend confessed that this next idea was put into his head by a Russian colleague who informed him of the ancient Balnibarbian custom of carrying the remnants of one's ancestors for seven years. The remains encouraged a perpetual contemplation of the wisdom of the elders. It occurred to me that this model might serve our purposes well. I say we require graduate students to serve a probationary period in the company of our late friends. This would be a binding agreement between mentor and disciple for the duration of their residency as graduate students (perhaps our friends in engineering could design a special harness). I assure you this will instill in them a sense of the responsibility to their academy and limit their capacity for fanciful pedagogical behavior. The university, as a result, would not be for the worse.

I profess with all sincerity that I have no self interest in putting forth this necessary plan. And in fact, let me be the first to submit my body and soul to this endeavor, in the interest of a reinvigorated institution. 